\title{
Morphological control of calcium phosphate nanostructures using lyotropic liquid crystals $\uparrow$
}

Cite this: J. Mater. Chem. B, 2014, 2 , 3214

Received 15th January 2014 Accepted 19th March 2014

DOI: $10.1039 / c 4 t b 00095 a$

www.rsc.org/MaterialsB

\begin{abstract}
Wenxiao He, Yu Fu and Martin Andersson*
Organisms use "soft" organic compartments to control the morphology of the embedded "hard" minerals. Here we present a simple method using liquid crystal (LC) phases as "soft" and "inert" templates to prepare nanostructured calcium phosphates (CaPs), which are inorganics of known bioefficacy. Specifically, $6 \mathrm{~nm}$ thick CaP nanowires and CaP sheets that precisely replicate reverse hexagonal $\left(\mathrm{H}_{2}\right)$ and lamellar $\left(\mathrm{L}_{\alpha}\right) \mathrm{LCs}$ have been successfully synthesized and we attribute this to the sufficient spatial regulation offered by the negative $\left(\mathrm{H}_{2}\right)$ or flat curvature $\left(\mathrm{L}_{\alpha}\right)$ of the aqueous domain. A normal hexagonal $\left(\mathrm{H}_{1}\right)$ phase possesses a positive curvature of the aqueous domain, therefore limited spatial restriction. For this reason, precise replication of the $\mathrm{H}_{1}$ phase by $\mathrm{CaP}$ has not been possible. Interestingly, the dynamic nature of the template allowed the construction of micron-sized brushite objects with a laminated structure decorating a specific facet, possibly as a result of epitaxial overgrowth of nano-sized brushite subunits.
\end{abstract}

\section{Introduction}

Skeletal biominerals possess distinctive morphological, compositional, crystallographic features and organizational order, and thereby exhibit superior material properties. An eminent example is the mineral phase in mammalian bone. Bone apatite nanoplatelets (a highly substituted polymorph of calcium phosphate, $\mathrm{CaP}$ ) uniaxially align within the collagen matrix, which provide mammals optimal protection, support and other specialized functions. ${ }^{1}$ The synthesis of these biominerals mostly proceeds within micro- to nano-scopic compartments, i.e. structural matrix assembled by insoluble biomacromolecules. ${ }^{1-4}$ In addition to the spatial confinement, soluble components including ions and nonstructural biomacromolecules synergistically modulate the mineralization process. ${ }^{1-4}$ To elucidate the geometric effects in tuning the morphology and polymorphism of biominerals, herein, we report the "softly" confined morphogenesis of CaPs into wellaligned nanowires, nanosheets, ordered laminated structures in "inert" liquid crystal (LC) phases, as well as a site-specificdecoration strategy to construct $\mathrm{CaP}$ superstructures with ordered nano-features. The precise control of CaP nanostructures by gentle spatial confinement and the possibility to add-on the structure onto pre-existing architectures offers new opportunities for rational design of nano-inorganics and hybrid

Department of Chemical and Biological Engineering, Chalmers University of Technology, Göteborg SE-41296, Sweden. E-mail: martin.andersson@chalmers.se $\dagger$ Electronic supplementary information (ESI) available: Experimental setup, the supplementary micrographs of CaP particles synthesized in $\mathrm{H}_{2}$ LC, SEM images of the introduction of CaP nuclei in $\mathrm{H}_{1}$ gel, and scheme of the proposed mechanism for CaP brick/object formation. See DOI: 10.1039/c4tb00095a materials for advanced applications including artificial bone, biocompatible sensing and nanophotonic devices.

With compositions close to the bone mineral and widely recognized bioefficacy, $\mathrm{CaP}$ has been the predominant mineral family utilized in biomedical research and industry, where researchers have endeavored to obtain CaP materials with welldefined structures. ${ }^{5,6}$ Amorphous calcium phosphate (ACP), dicalcium phosphate (dihydrate: DCPD, brushite; anhydrous: DCPA, monetite), octacalcium phosphate (OCP), and calcium deficient hydroxyapatite (CDHA) are the CaP phases that can be formed under near-physiological conditions (in the $\mathrm{pH}$ range of 6-8 at room temperature and air pressure) and therefore retain biological relevance. ${ }^{5,7-10}$ The anisotropic crystal growth of CaP polymorphs is counterproductive to morphological control. ${ }^{11}$ Moreover, the competition between CaP phases during precipitation further introduces complexity for controlled morphogenesis. Strategies including utilizing active additive/templateCaP interaction, biological templates and hard templates have been adopted to actively and/or geometrically regulate $\mathrm{CaP}$ growth. ${ }^{12-17}$ However, these approaches have several limitations: as in the case of using active additive/templates, specially designed macromolecules that could direct $\mathrm{CaP}$ nucleation and crystallization are needed; while in the case of biological templates, an additional precursor infiltration step as well as matrices from restricted sources like demineralized biological samples are required; whereas for hard templates, the structural rigorousity of the templates cannot truly reflect "soft" biological confinements and superstructures cannot be developed from them. On the other hand, synthetic hydrogels with structural flexibility have long been used as scaffolds for biomimetic mineralization, yet, the lack of an ordered nanostructure in most systems does not allow precise control over 
CaP morphologies. LC phases possessing well-organized nanometric aqueous domains are ideal matrices for biomimetic mineralization, as in natural bone the collagen matrix is itself essentially a LC. Yet there are few reports on the successful replication of $\mathrm{CaP}$ from LC phases, as forces holding the LC structure (hydrophobic interaction between self-assembled amphiphilic polymers) can be too weak to restrain anisotropic growth of crystalline CaPs. ${ }^{18}$ To overcome this, our previous strategy was to biomimetically employ an amorphous intermediate phase. Specifically, reverse hexagonal $\left(\mathrm{H}_{2}\right)$ LC was used to synthesize uniform ACP nanospheres, from which apatite nanoparticles with well-defined morphology and bone-resembling features were prepared through controlled crystallization. ${ }^{19}$

The current study focuses on the manipulation of $\mathrm{CaP}$ morphogenesis and polymorphism in confined nanospace provided by $\mathrm{H}_{2}$, lamellar $\left(\mathrm{L}_{\alpha}\right)$ and normal hexagonal $\left(\mathrm{H}_{1}\right)$ LCs. We show that a commercially available nonionic block-copolymer can be used to construct matrices with varied degree of spatial confinement, so that it can guide CaP growth into ACP, monetite (DCPA) or brushite (DCPD) with morphologies replicating the matrix (Fig. 1). The choice of nonionic block-copolymer assemblies may on one hand purely provide spatial restriction during mineralization without active polymercrystal interaction, thus the technique and outcome can be translated to other compartmentalized matrices; on the other hand, it may also allow re-arrangement of the template structure during particle growth. The flexibility of this system enables us to produce brushite crystals with hierarchical structures (Fig. 1, $\mathrm{H}_{1}$ ).

\section{Experimental}

\subsection{LC gel preparation}

All chemicals were of analytical grade, purchased from SigmaAldrich (except Pluronic F127, which was kindly donated by

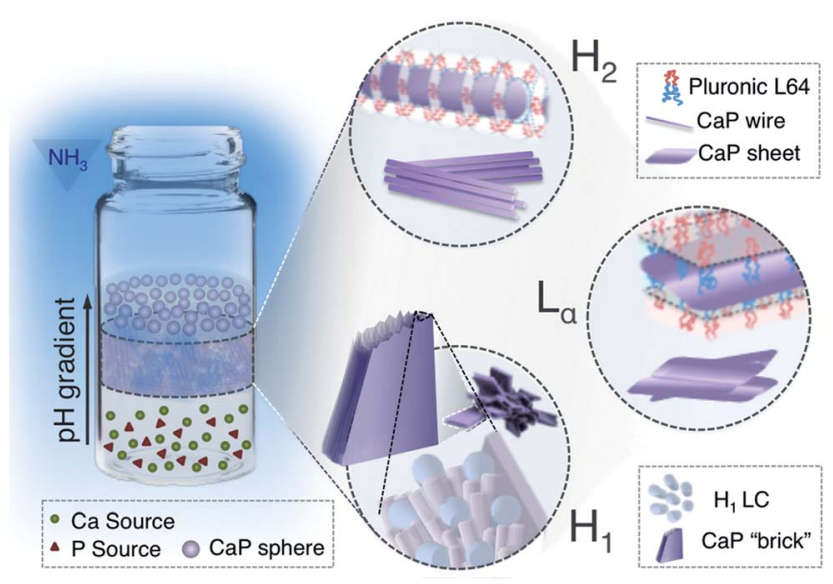

Fig. 1 Illustration of the morphological development of CaP particles in $\mathrm{H}_{2}, \mathrm{~L}_{\alpha}$ and $\mathrm{H}_{1}$ LC phase, where a kinetic window exists for $\mathrm{CaP}$ growth to replicate the template structure or to build up the CaP superstructure. The sizes of CaPs and templates are exaggerated for illustration.
BASF) and used without further purification. Pluronic L64 $\left(\mathrm{EO}_{13} \mathrm{PO}_{30} \mathrm{EO}_{13}\right)$ and $\mathrm{F} 127\left(\mathrm{EO}_{100} \mathrm{PO}_{70} \mathrm{EO}_{100}\right)$ were utilized to form different LC phases. $\mathrm{Ca}\left(\mathrm{NO}_{3}\right)_{2} \cdot 4 \mathrm{H}_{2} \mathrm{O}(0.84 \mathrm{M})$ and $\mathrm{H}_{3} \mathrm{PO}_{4}$ with a $\mathrm{Ca} / \mathrm{P}$ molar ratio of 1.67 were dissolved in Milli-Q water. To form a LC gel with the desired structure, pre-mixed precursor solution, Pluronics and oil were mixed evenly according to the recipes listed in Table $1 .^{20,21}$ Gel samples with a thickness of $c a$. $1 \mathrm{~mm}, 2.5 \mathrm{~mm}$ or $35-40 \mathrm{~mm}$ were prepared by filling glass vials $(20 \mathrm{~mL}, 57.00 \times 27.50 \mathrm{~mm}$, VWR $)$ with $c a .0 .4 \mathrm{~g}, 1 \mathrm{~g}$ or $15 \mathrm{~g}$ of the as-formed liquid crystalline (LC) gel having the desired structure. In one of the glass vials, $\mathrm{pH}$ paper ( $\mathrm{pH}$ range: 1-11 or 1-14) was cut into small pieces and mixed with the LC gel, which was later on used as a $\mathrm{pH}$ indicator for the reaction (as shown in Fig. S1c, ESI $\dagger$ ).

\subsection{Reaction in ammonia atmosphere}

After preparation, the glass vials were tightly sealed and stored for $24 \mathrm{~h}$ to reach equilibrium. An additional sonication step (sonication bath, $60 \mathrm{~min}$ ) was applied to the Pluronic F127based $\mathrm{H}_{1}$ gel sample. After that, the gels were placed in the desiccator cabinet $(7 \times 12 \times 12$ inch $)$ with an ammonia atmosphere, as illustrated in the ESI Fig. S1a, $\uparrow$ where the beaker in the lower part contained varied concentrations and volumes of ammonium hydroxide solution. By diffusion of ammonia gas into the LC gel, CaP precipitated from the aqueous domain of the LC phase. After 24-72 h, the glass vials were taken out from the desiccator cabinet and gel samples were collected accordingly to their depth from upper gel surface (Fig. S1c, ESI $\dagger$ ) or pH ranges ( $\mathrm{pH}$ value of gel layers at certain depths was read from the $\mathrm{pH}$ indicator, as shown in Fig. S1c $\dagger$ ). The collected gel samples were dispersed in ethanol and centrifuged (Hettich ALC) for $10 \mathrm{~min}(1585 \times g, 2500 \mathrm{rpm})$. Then the supernatant was removed gently and the sedimentation was re-dispersed in ethanol. This purification process was repeated at least 3 times.

\subsection{Characterization}

Transmission electron microscopy (TEM) analysis was performed on a JEOL 1200EX II microscope operating at $120 \mathrm{kV}$. The TEM specimens were prepared on a lacey carbon coated copper grid by evaporating a drop of CaP suspension in ethanol. Scanning electron microscopy (SEM) was also performed on the

Table 1 Recipes of LC gel with varied phase structures prepared from L64-water-p-xylene and F127-water-butanol systems ${ }^{20,21}$

\begin{tabular}{lllll}
\hline & & \multicolumn{2}{l}{ Composition (wt\%) } \\
\cline { 3 - 5 } No. & Phase structure $^{a}$ & L64 & $p$-Xylene & Precursor solution \\
\hline L-1 & $\mathrm{H}_{2}$ & 70 & 15 & 15 \\
L-2 & $\mathrm{L}_{\alpha}$ & 70 & 0 & 30 \\
L-3 & $\mathrm{L}_{\alpha}$ & 55 & 10 & 35 \\
L-4 & $\mathrm{H}_{1}$ & 55 & 0 & 45 \\
& & F127 & Butanol & Precursor solution \\
F-1 & $\mathrm{H}_{1}$ & 60 & 16 & 24
\end{tabular}

${ }^{a} \mathrm{~L}_{\alpha}, \mathrm{H}_{1}$, and $\mathrm{H}_{2}$ denote lamellar, normal hexagonal and reverse hexagonal LC phases, respectively. 
TEM sample grid (by sticking onto SEM stub using carbon tape), using a LEO ULTRA 55 FEG at an accelerating voltage of 2 or 5 $\mathrm{kV}$. X-ray powder diffraction (XRD) patterns were recorded using a Bruker $\mathrm{D} 8 \mathrm{Advance} \mathrm{X}$-ray diffractometer with $\mathrm{Cu}-\mathrm{K} \alpha_{1}$ radiation $(\lambda=1.54056 \AA)$. All the crystalline phases were identified and semi-quantitatively analysed based on reference intensity ratio (RIR) values using the Search/Match module of DIFFRAC EVA (Bruker AXS) and ICDD database. Small Angle X-ray Scattering (SAXS) experiments were performed on the prepared LC gels before and after the synthesis using synchrotron radiation. The experiments were performed at the 1911 beamline at MAX-lab (Lund, Sweden). The wavelength was $0.91 \AA$ and a two-dimensional MarCCD $165 \mathrm{~mm}$ detector was used. Samples were sealed in a slit ( $1 \mathrm{~mm}$ thick) enclosed by two parallel transparent cellophane films within a stainless steel sample holder mounted in an evacuated sample chamber. The data were collected for 60-180 s and the used $q$-range $(q=4 \pi \sin \theta / \lambda)$ was $0.1-4.0 \mathrm{~nm}^{-1}$.

\section{Results and discussion}

TEM studies of CaP particles grown from a Pluronic L64-based $\mathrm{H}_{2}$ LC gel presented varied morphologies depending on the

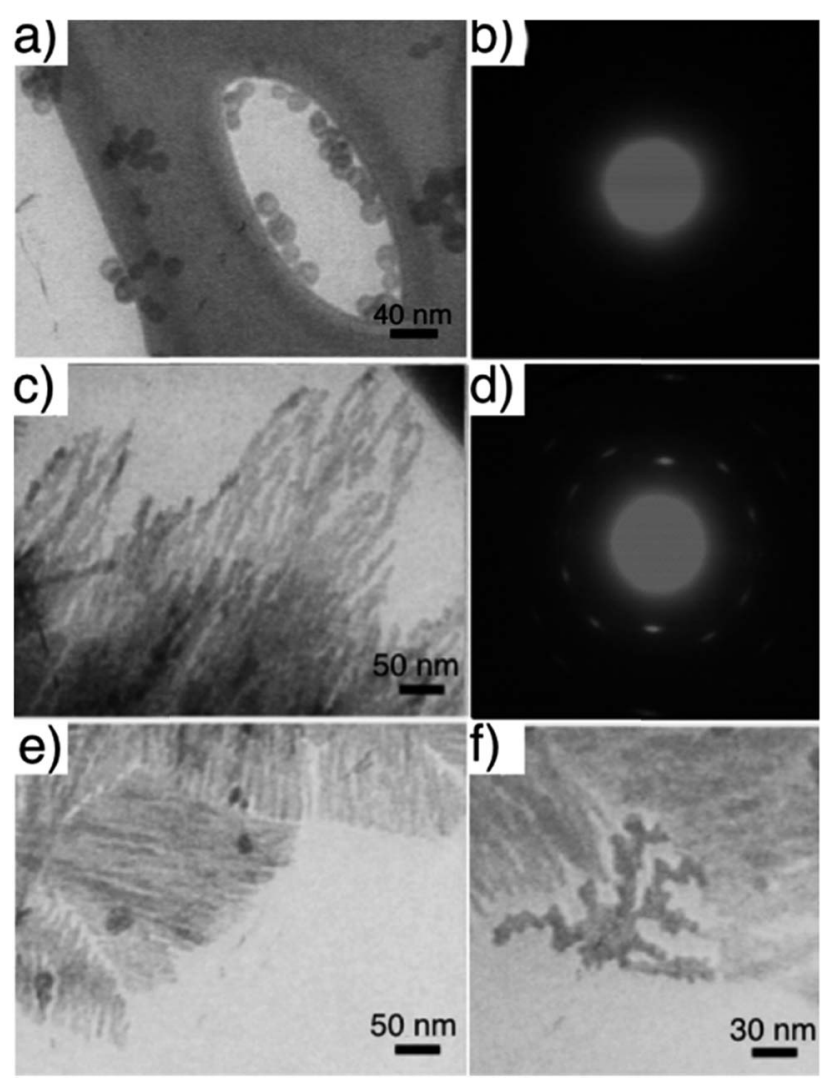

Fig. 2 TEM images of CaP particles obtained from $\mathrm{H}_{2} \mathrm{LC}$ gel when collected from (a) upper $3 \mathrm{~mm}$-thick gel after $48 \mathrm{~h}$ and (b) the corresponding SAED pattern, (c) gel layer $3-6 \mathrm{~mm}$ below the surface after $72 \mathrm{~h}$ and (d) the corresponding SAED pattern, (e) and (f) same condition as (c) but with a gel equilibration time of $10 \mathrm{~h}$ instead of $24 \mathrm{~h}$. Gel recipe: $L-1$ in Table 1 . Gel thickness: $35-40 \mathrm{~mm}$. Ammonia dose: $300 \mathrm{~mL} 35 \mathrm{wt} \% \mathrm{NH}_{3} \mathrm{OH}$ solution. sampling time point and position. CaP nanospheres with a diameter of roughly $11 \mathrm{~nm}$ formed exclusively in the upper 3 mm-thick gel layer (Fig. 2a) after $48 \mathrm{~h}$ of reaction. The corresponding selected area electron diffraction (SAED) pattern (Fig. 2b) shows that they are ACP, which agrees with our earlier observation with half the precursor concentration. ${ }^{19}$

In the gel layer 3-6 mm below the surface, CaP particles with unsettled morphologies (Fig. S2a, ESI $\dagger$ ) were harvested after 24 $\mathrm{h}$ of reaction, indicating an early structural development. Whereas after $48 \mathrm{~h}$ of reaction, CaP nanowires with a diameter of ca. $6 \mathrm{~nm}$ (Fig. S2b, ESI $\dagger$ ) were formed, together with ACP nanospheres. With a prolonged reaction time of $72 \mathrm{~h}$, the nanowire shape of CaPs (Fig. 2c) retained in the same sampling position. The electron diffraction pattern of these nanowire arrays (Fig. 2d) unveils the crystallinity of the sample. The arclike diffraction spots indicate the presence of crystallographic orientation within the nanowire arrays. However, it has been difficult to resolve the CaP phase by XRD analysis (Fig. 3a), in which the diffuse pattern implies relative low abundance and poor crystallinity of the nanowires. Yet the star-marked region in the diffractogram might suggest a monetite phase of the nanowires. These nanowire arrays seem to align in the gel as observed under optical microscopy (Fig. S3, ESI $\dagger$ ), in which each hair-like feature represents an assembly of CaP nanowires.

Similar experiments with a shorter gel equilibration time (instead of the $24 \mathrm{~h}$ used for general cases) were performed to test the templating effect of the LC gel, as a limited gel equilibration time would result in smaller ordered domains with different orientations in the original LC templates. As expected,

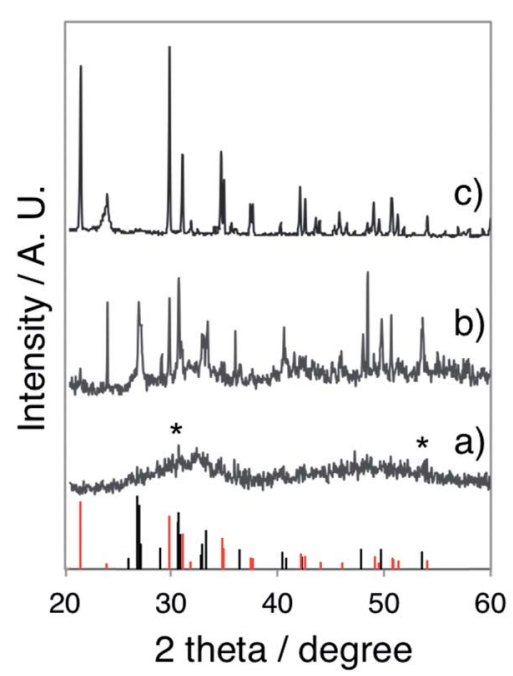

Fig. 3 XRD pattern of (a) the CaP nanowires obtained from the gel layer 3-6 mm below the surface of a 35-40 $\mathrm{mm}$ thick $\mathrm{H}_{2} \mathrm{LC}$ gel after $72 \mathrm{~h}$ of reaction (gel recipe: Table $1 \mathrm{~L}-1$, ammonia dose: $300 \mathrm{~mL} 35 \mathrm{wt}$ $\% \mathrm{NH}_{3} \mathrm{OH}$ solution), (b) the $\mathrm{CaP}$ sheets obtained from the gel layer with $\mathrm{pH} 9$ of a $35-40 \mathrm{~mm}$ thick $L_{\alpha}$ sample after 24 h of reaction (gel recipe: Table $1 \mathrm{~L}-3$, ammonia dose: $80 \mathrm{~mL} 35 \mathrm{wt} \% \mathrm{NH}_{3} \mathrm{OH}$ solution), and (c) the CaP bricks obtained from the gel layer $12-15 \mathrm{~mm}$ below the surface $(\mathrm{pH} 9-10)$ of a $35-40 \mathrm{~mm}$ thick $\mathrm{H}_{1} \mathrm{LC}$ after $48 \mathrm{~h}$ of reaction (gel recipe: Table $1 \mathrm{~F}-1$, ammonia dose: $80 \mathrm{~mL} 35 \mathrm{wt} \% \mathrm{NH}_{3} \mathrm{OH}$ solution.). Bottom: the standard monetite (black) and brushite (red) data. Diffractograms have been vertically shifted for clarity. 
with a gel equilibration time of $10 \mathrm{~h}$, smaller domains of CaP wire stacks (Fig. 2e) were obtained from gel layer of 3-6 mm after $72 \mathrm{~h}$ of reaction. In addition, dendrimeric CaP particles were also found in between the ordered domains (Fig. 2f), which reflect the defects in the $\mathrm{H}_{2}$ LC template due to incomplete equilibration.

The disparity in particle morphologies and polymorphism in different gel layers can be linked to differences in the $\mathrm{pH}$ profile within the aqueous domains of the LC gel. The spherical morphology and slightly larger particle diameter (than that of the original water channels which is $c a .6 \mathrm{~nm}$ ) of ACPs formed in the upper layer implies a fast kinetic precipitation. ${ }^{19}$ While in the intermediate layers, the morphology of the water domains were replicated directly to crystalline nanowires, suggesting a

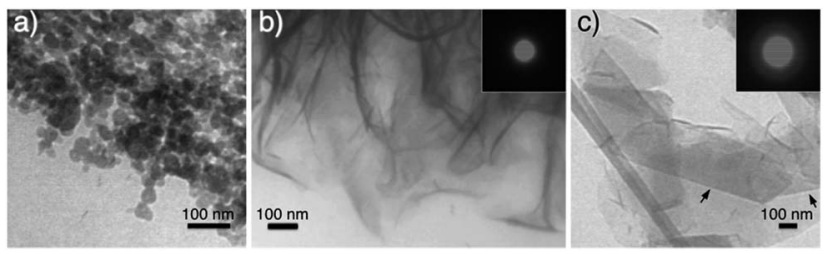

Fig. 4 TEM images of CaPs obtained after $24 \mathrm{~h}$ from ca. $1 \mathrm{~mm}$-thick $L_{\alpha}$ LC gel with ammonia doses of (a) $800 \mathrm{~mL} 0.196$ wt\% $\mathrm{NH}_{3} \mathrm{OH}$ solution, (b) $800 \mathrm{~mL} 0.068 \mathrm{wt} \% \mathrm{NH}_{3} \mathrm{OH}$ solution (SAED pattern inserted), and (c) from the gel layer with $\mathrm{pH} 8-9$ of a $35-40 \mathrm{~mm}$ thick sample with $80 \mathrm{~mL} 35 \mathrm{wt} \% \mathrm{NH}_{3} \mathrm{OH}$ solution in a $\mathrm{pH}$ beaker (SAED pattern inserted). Gel recipe: L-2 ( $a$ and $b$ ) and L-3 (c) in Table 1. moderate $\mathrm{pH}$ increase that is slow enough for nucleation in an acidic environment, yet fast enough to allow a kinetic driven crystal growth with controlled shape. The moderate $\mathrm{pH}$ rise in the intermediate layer was due to the presence of CaP particles formed in the upper gel layer that slowed down the ammonia penetration. The particles formed in a deeper gel layer, i.e. with an even slower $\mathrm{pH}$ increase, presented ill-templated shapes (data not shown) due to higher tendency toward crystallization.

To further elucidate the sensitivity of CaP morphogenesis to pH-rate, we performed experiments using the L64-based $\mathrm{L}_{\alpha} \mathrm{LC}$ phase with a gel thickness of $c a .1 \mathrm{~mm}$. An ammonia dose of 800 $\mathrm{mL} 0.196$ wt\% $\mathrm{NH}_{3} \mathrm{OH}$ solution (in the $\mathrm{pH}$ beaker within desiccator) resulted in spherical CaP aggregates (Fig. 4a) in the $\mathrm{L}_{\alpha}$ gel (final $\mathrm{pH} 10$ ) after $24 \mathrm{~h}$ of reaction, corresponding to the upper layer observed in the thick gel samples. With a lower ammonia dose ( $800 \mathrm{~mL} 0.068 \mathrm{wt} \% \mathrm{NH}_{3} \mathrm{OH}$ solution), foiled $\mathrm{CaP}$ sheets (Fig. 4b) that replicated the water domain of the $\mathrm{L}_{\alpha}$ gel (final pH 8-9) were formed. The absence of diffraction spots and rings in the electron diffractogram (the inset in Fig. 4b) shows that these CaP sheets were amorphous. For comparison, we also performed experiments using 35-40 $\mathrm{mm}$ thick $\mathrm{L}_{\alpha}$ gel samples for $24 \mathrm{~h}$ and with a more concentrated ammonia atmosphere ( $80 \mathrm{~mL} 35 \mathrm{wt} \% \mathrm{NH}_{3} \mathrm{OH}$ solution in $\mathrm{pH}$ beaker). As expected, spherical CaP aggregates and foiled $\mathrm{CaP}$ sheets were found in the gel layer with $\mathrm{pH} 10$ and $\mathrm{pH}$ 8-9, respectively (data not shown). Interestingly, some of the CaP sheets presented more rigid folding lines (as indicated by black arrows in Fig. 4c) than the others. The barely visible diffuse diffraction ring in the
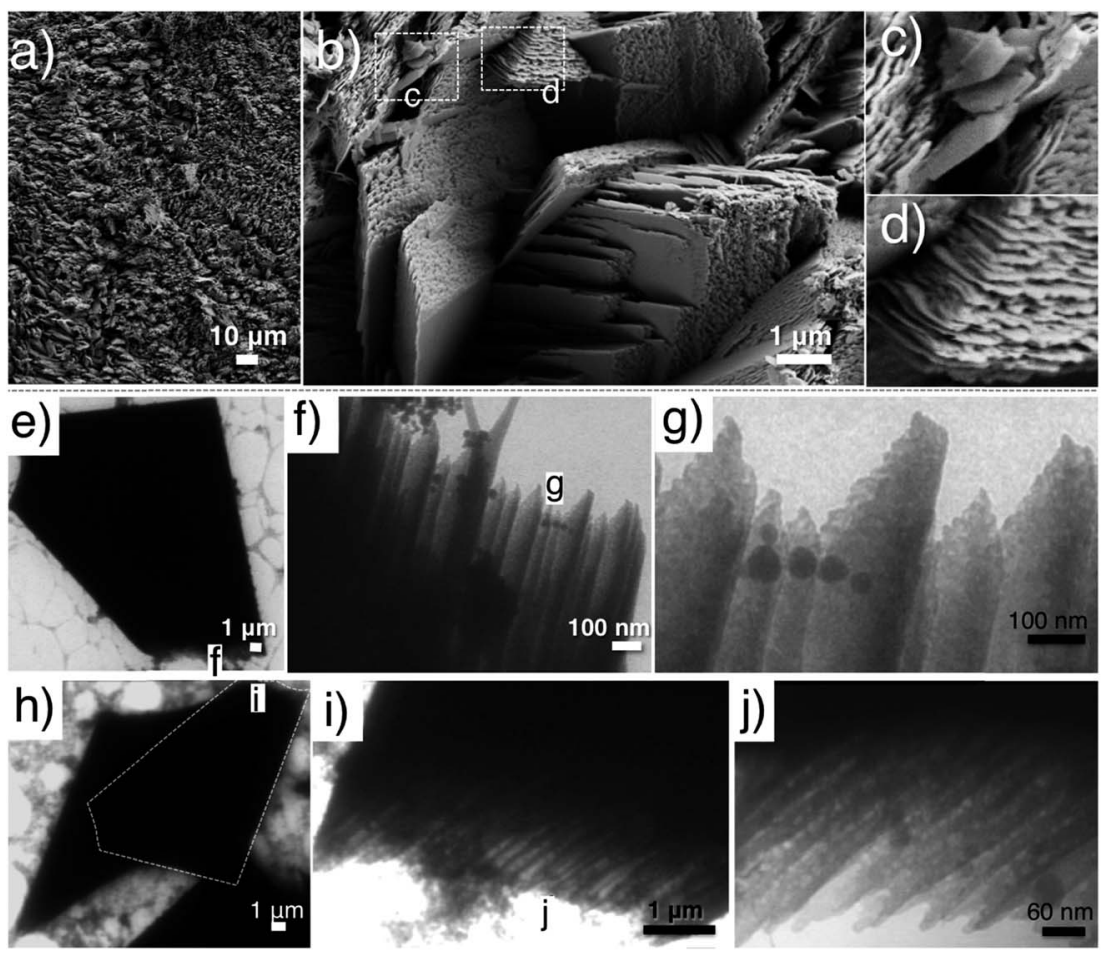

Fig. 5 (a-d) SEM images of laminated CaP sheets obtained from the upper crust of a $2.5 \mathrm{~mm}$ thick $\mathrm{H}_{1} \mathrm{LC}$ after $24 \mathrm{~h}$ of reaction; (e-j) TEM images of CaP bricks obtained from the layer 12-15 mm below the gel surface (pH 9-10) of a 35-40 mm thick $\mathrm{H}_{1} \mathrm{LC}$ after $48 \mathrm{~h}$ of reaction. Gel recipe: L-4 (a-d), F-1 (e-j) in Table 1. Ammonia dose: (a-d) $800 \mathrm{~mL} 0.33 \mathrm{wt} \% \mathrm{NH}_{3} \mathrm{OH}$ solution, and (e-j) $80 \mathrm{~mL} 35 \mathrm{wt} \% \mathrm{NH}_{3} \mathrm{OH}$ solution. Squares and inserted letters mark the magnified region. 
SAED pattern (the inset in Fig. 4c) might suggest the presence of crystallinity in these sheets. However, a clear electron diffraction pattern of this area was not attainable due to the extremely small sample thickness and lability under an electron beam. The XRD pattern (Fig. 3b) reveals that these rigid sheets are dicalcium phosphate (DCP) either with (DCPD, brushite) or without lattice water (DCPA, monetite) with the DCPA/DCPD mass fraction ratio of roughly 2.4 .

With a continuous aqueous domain and a high water content, controlled morphogenesis of CaP in the L64-based $\mathrm{H}_{1}$ LC phase with a sample thickness of $c a .2 .5 \mathrm{~mm}$ and ammonia dose of $800 \mathrm{~mL} 0.33 \mathrm{wt} \% \mathrm{NH}_{3} \mathrm{OH}$ solution in the $\mathrm{pH}$ beaker seemed to be a failure, as submillimeter-sized crust-like CaP aggregates (Fig. 5a) were formed in the upper gel layer ( $\left.\mathrm{pH}^{8-9}\right)$ that greatly blocked the further penetration of ammonia gas. Nevertheless, a higher magnification reveals the laminated details of the CaP aggregates (Fig. 5b), where stacks of CaP plates closely pack together. The debris from broken pieces
(Fig. 5c) further discloses the thin flake-like morphology of CaP subunits. In addition, the CaP plates within a stack are packed so well that their edges seem to align into flat faces with straight ridges (Fig. 5d). A possible construction principle of this laminated structure would be the epitaxial overgrowth of highly oriented layered CaP crystal subunits on an underlying substrate composed of large CaP single crystals that expose a specific facet facing different directions.

To demonstrate the proposed construction principle of laminated CaP sheets, experiments using a Pluronic F127-based $\mathrm{H}_{1}$ LC phase with an additional sonication step prior to the reaction in the desiccator were conducted. The F127-based $\mathrm{H}_{1}$ LC contains butanol as the oil phase that would assist ammonia penetration through a thick gel system, thus causing a smooth $\mathrm{pH}$ rise within the gel layer. ${ }^{21}$ Furthermore, the additional sonication step introduces crystal nuclei to the system (Fig. S4a, $\mathrm{ESI} \dagger$ ), which then grow into larger crystal aggregates (Fig. S4b and $c^{\dagger}$ ). This approach allowed us to investigate the facets CaP
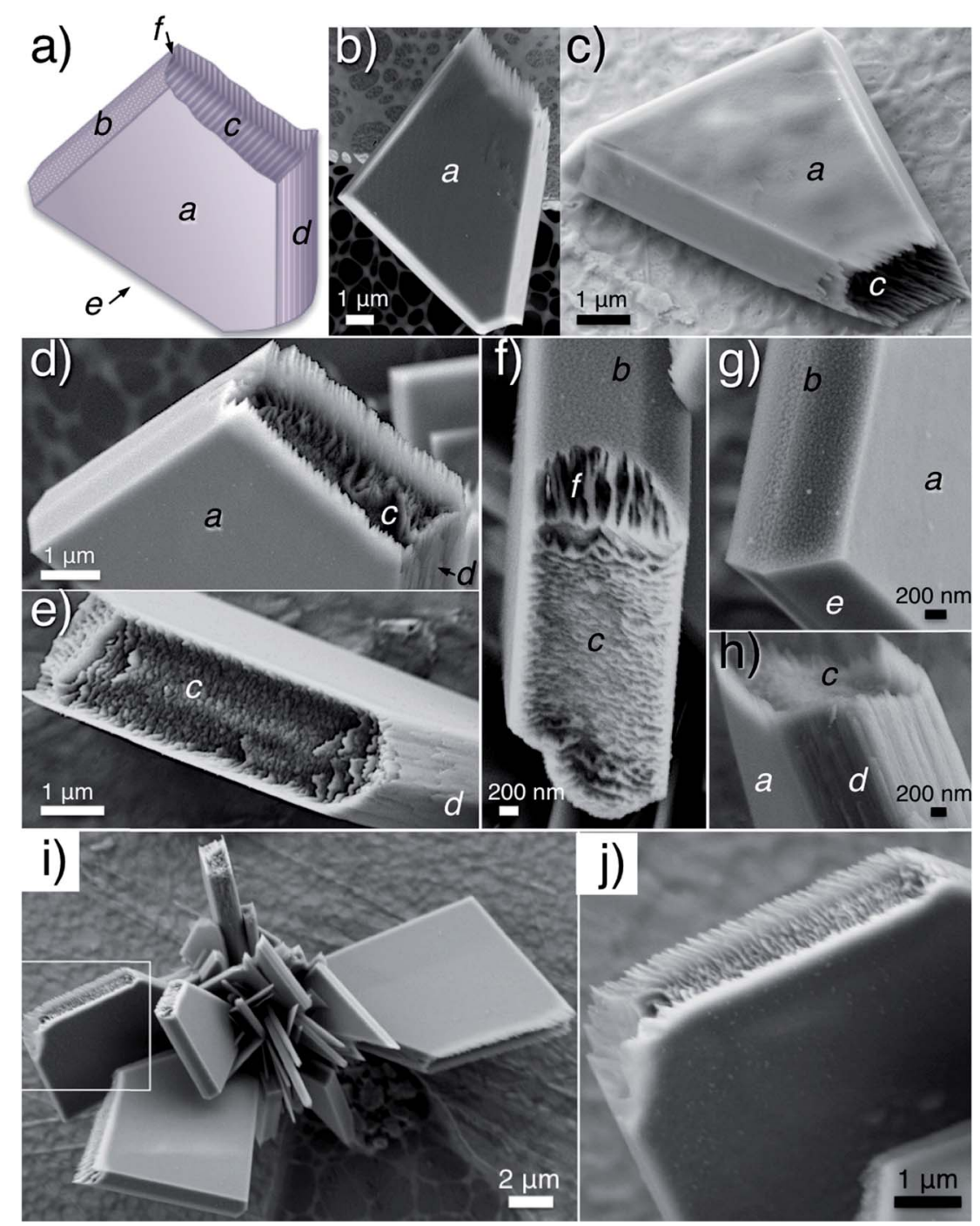

Fig. 6 (a-h) SEM micrographs revealed the all-around details of the CaP bricks and (i and j) SEM images of a CaP object composed of several CaP bricks. Samples were prepared and collected with the same condition as the ones shown in Fig. 5e-j. Inserted italic letters index the different "facets" of the brick. Squares mark the magnified region. 
subunit overgrowth that developed. Specifically, ca. 35-40 $\mathrm{mm}$ thick $\mathrm{H}_{1}$ LC samples (recipe: F-1, Table 1) were first subjected to sonication for $60 \mathrm{~min}$, and then reacted in a concentrated ammonia atmosphere $\left(80 \mathrm{~mL} 35 \mathrm{wt} \% \mathrm{NH}_{3} \mathrm{OH}\right.$ solution in $\mathrm{pH}$ beaker) for $48 \mathrm{~h}$ and from which the gel layers of 12-15 mm below the surface ( $\mathrm{pH}$ 9-10) were collected. Fig. 5e and h show the typical TEM images of as-synthesized CaP "bricks", in which a trapezium-like pentagon shape was presented. A higher magnification discloses the inner hierarchy of the shorter parallel "edge" of the trapezium (Fig. 5f, g, i and j).

The SEM studies depict the topography of such CaP "bricks" in detail (Fig. 6a-h), where smooth facets ( $a$ - and $e$ facet and the corresponding twin facets marked in Fig. 6a-d, $\mathrm{g}$ and $\mathrm{h}$ ), grainy facets ( $b$ - and twin facets marked in Fig. 6a, $\mathrm{f}$ and $\mathrm{g}$ ), striated facets ( $d$ - and twin facet marked in Fig. 6a, d, e and $h$ ), as well as laminated sides ( $c$ - and twin facets marked in Fig. 6a, c-f and h; occasionally exposed $f$ - and twin facets marked in Fig. $6 \mathrm{a}$ and $\mathrm{f}$ ) were presented together in the same brick. The narrow peaks in the XRD pattern confirm that the CaP brick comprises of highly crystalline brushite (Fig. 3c, phase pure). The $a-, b$-, $d$ - and $e$-facet of the brick marked in Fig. 6a could be $(h k l)$ indexed as (010), (111), (120), (111) and the corresponding mirror facets with $\{010\}$ as the twin plane, respectively, of pure brushite. ${ }^{22,23} \mathrm{We}$ highlight that the $c$-side from SEM investigation (Fig. 6a) constantly happens to be the shorter parallel "edge" of the trapezium from TEM studies (Fig. 5e and h), where the laminated feature of the $c$ side (Fig. 6c-f and $\mathrm{h}$ ) reconciles with the inner hierarchy presented on the shorter parallel "edge" in TEM images (Fig. 5f, g, i and j).

In addition to single brushite bricks, 15-25 micron-sized objects comprised of several bricks were observed abundantly in the sample (Fig. 6i and j). The evolution of these superstructures, disclosed by SEM, starts from a crystalline cluster formed by sonication-induced spontaneous precipitation within the highly saturated acidic precursor solution (Fig. S4a, ESI $\dagger$ ). This then grows into large polycrystalline aggregates under further sonication (Fig. S4b and $\mathrm{c}^{\dagger}$ ); and finally, each petal of the polycrystalline aggregate develops crystalline facets as well as a laminated structure on the $c$-side under an ammonia atmosphere (Fig. S4d, ESI $\dagger$ ).

In an attempt to distinguish the laminated structure from the bulk single crystal of a brushite brick, the as-prepared brushite objects were subjected to a gentle grinding process using an agate mortar ( $5 \mathrm{~min}$ ) in the presence of several drops of ethanol. Fig. 7a and c show the typical morphology of brushite objects after grinding. SEM images at higher magnification (Fig. 7b and d) unveil the $c$-side of brushite bricks after grinding, where the spaghetti-like patterns in Fig. $7 \mathrm{~b}$ are the edges of disordered brushite subunits on the $c$-side after grinding. While in Fig. 7d, both bumpy solid surfaces (upper-left region) and attached distorted flakes with thickness on the order of $20 \mathrm{~nm}$ (lower-right region) on $c$-side are observed. The former can be assigned to the bulk single crystal of the brushite brick while the latter are distinctly the remaining brushite subunits after grinding. All of these features favor for our assumption of an epitaxially grown layer of brushite flake subunits on top of the

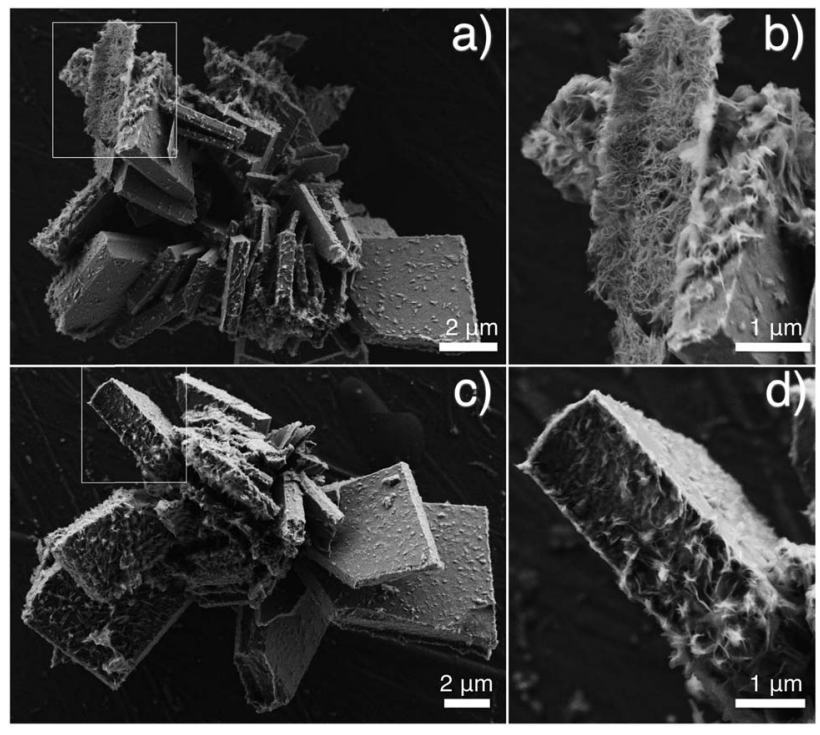

Fig. 7 SEM images of the as-prepared CaP objects after gentle grinding (agate mortar, 5 min, with drops of ethanol). Squares mark the magnified region.

brushite bulk brick, as illustrated in Scheme S1.† The epitaxial growth of ordered subunits from the crystalline bulk has been previously observed for calcium carbonate. ${ }^{2425}$ Additionally, $\mathrm{CaP}$ with channel-like features resulting from the packing of brushite subunits has also been reported. ${ }^{26}$ However, these studies all require the interplay between ionic polymers and the crystals, while in our system, the structure is dependent solely on spatial confinement.

Finally, SAXS analysis confirmed the presence of the LC phase (F127 based $\mathrm{H}_{1} \mathrm{LC}$, L64 based $\mathrm{H}_{2}$ and $\mathrm{L}_{\alpha} \mathrm{LC}$, respectively) in the early stage of CaP structural development, as SAXS patterns (Fig. 8) with peak positions associated with the different LC structures were maintained in the collected gel layers $(\mathrm{pH} 7$ or $\mathrm{pH} 8)$ after reaction for $48 \mathrm{~h}\left(\mathrm{~L}_{\alpha}\right)$ or $72 \mathrm{~h}\left(\mathrm{H}_{1}\right.$ and $\mathrm{H}_{2}$ ), together with an initial slope indicating the particle formation within each LC.

In the current system, ACP, DCPA and DCPD are the three major phases competing in the process of precipitation. ACP, with the isotropic nature, i.e. possibility to replicate any shape, is favorable for controlled morphogenesis, while the anisotropicity of DCPs encumbers it, as the preferential growth could break down the LC template organized via hydrophobic interaction. ${ }^{11}$ We show that it is possible to precisely template $\mathrm{CaP}$ in $\mathrm{H}_{2}$ (Fig. 2c, e and f) and $\mathrm{L}_{\alpha}$ (Fig. $4 \mathrm{~b}$ and c) LC phases and we associate this to the negative $\left(\mathrm{H}_{2}\right)$ or flat curvature $\left(\mathrm{L}_{\alpha}\right)$ of the aqueous domains, as they offer sufficient spatial regulation on the growth of ACP and even DCPs. However, accurate CaP replication of the $\mathrm{H}_{1}$ LC structure was not attainable, due to the positive curvature of the aqueous domain in the $\mathrm{H}_{1}$ phase, providing less spatial confinement. Never the less, we demonstrate that LC re-assemblability provides the template with the ability to build up crystalline CaP with organized nano-patterns (Fig. 5 and 6). 

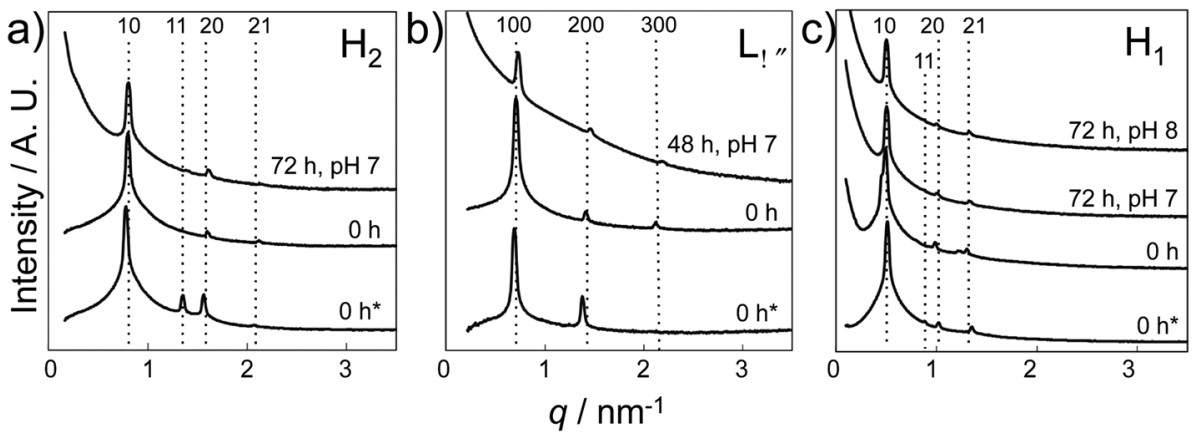

Fig. 8 SAXS results of various LC gels before and after the reaction. (a) $\mathrm{H}_{2} \mathrm{LC}$ gel prepared using L64 (recipe: Table $\left.1 \mathrm{~L}-1\right)$, (b) $\mathrm{L}_{\alpha} \mathrm{LC}$ gel prepared using L64 (recipe: Table $1 \mathrm{~L}-2$ ), and (c) $\mathrm{H}_{1}$ LC gel prepared using F127 (recipe: Table $1 \mathrm{~F}-1$ ). Gel thickness: $35-40 \mathrm{~mm}$. Samples were exposed to a $\mathrm{NH}_{3}$ atmosphere $\left(300 \mathrm{~mL} 35 \mathrm{wt} \% \mathrm{NH}_{3} \mathrm{OH}\right.$ solution in $\mathrm{pH}$ beaker) for 0 and $48 \mathrm{~h}$ or $72 \mathrm{~h}$ and were collected according to $\mathrm{pH}$ ( $0 \mathrm{~h} *$ refers to the $\mathrm{LC}$ gel prepared without $\mathrm{Ca}$ and $\mathrm{P}$ sources, while the rest refers to LC gels prepared with a precursor concentration of $\left.0.84 \mathrm{M} \mathrm{Ca}^{2+}\right)$. SAXS data have been vertically shifted for clarity.

\section{Conclusion}

In summary, crystalline CaP nanowires and nanosheets (both ACP and DCP) that respectively replicate a $\mathrm{H}_{2}$ and $\mathrm{L}_{\alpha}$ LC have been synthesized by a simple gas diffusion method with commercially available reactants. In addition, the method can be used to produce brushite objects with superstructure in a $\mathrm{H}_{1}$ LC. The generation of a laminated structure on brushite objects is facet-specific and possibly the result of brushite subunit epitaxial overgrowth. Control over the CaP morphology was achieved solely by spatial confinement, allowing the possibility of this methodology to be used with alternative components.

\section{Conflict of interest}

The authors declare no competing financial interest.

\section{Acknowledgements}

We acknowledge the Swedish Research Council and NanoSphere Centre/Formas for funding. We also thank MAX-lab (Lund, Sweden) for the allocation of beam time and assistance with SAXS measurements.

\section{References}

1 A.-W. Xu, Y. Ma and H. Colfen, J. Mater. Chem., 2007, 17, 415. 2 H. A. Lowenstam and S. Weine, On Biomineralization, Oxford University Press, New York, 1989.

3 B. R. Heywood and S. Mann, Adv. Mater., 1994, 6, 9.

4 S. Weiner and P. M. Dove, An Overview of Biomineralization Processes and the Problem of the Vital Effect, in Reviews in Mineralogy and Geochemistry; Biomineralization, ed. P. M. Dove, J. J. De Yoreo and S. Weiner, Mineralogical Society of America, 2003, vol. 54, p. 1.

5 S. V. Dorozhkin and M. Epple, Angew. Chem., Int. Ed., 2002, 41, 3130 .
6 M. Vallet-Regí and E. Ruiz-Hernández, Adv. Mater., 2011, 23, 5177.

7 R. Z. LeGeros, Z. Kardiol., 2001, 3, 116.

8 L. J. Wang and G. H. Nancollas, Chem. Rev., 2008, 108, 4628.

9 L. Wang and G. H. Nancollas, Dalton Trans., 2009, 2665.

10 A. Navrotsky, Proc. Natl. Acad. Sci. U. S. A., 2004, 101, 12096.

11 H. Cölfen, Angew. Chem., Int. Ed., 2008, 47, 2351.

12 S. R. Hall, H. Bolger and S. Mann, Chem. Commun., 2003, 2784.

13 H. Tlatlik, P. Simon, A. Kawska, D. Zahn and R. Kniep, Angew. Chem., Int. Ed., 2006, 45, 1905.

14 X. Wang, J. Zhuang, Q. Peng and Y. D. Li, Adv. Mater., 2006, 18, 2031.

15 F. Nudelman, K. Pieterse, A. George, P. H. H. Bomans, H. Friedrich, L. J. Brylka, P. A. J. Hilbers, G. de With and N. A. J. M. Sommerdijk, Nat. Mater., 2010, 9, 1004.

16 F. Nudelman and N. A. J. M. Sommerdijk, Angew. Chem., Int. Ed., 2012, 51, 6582.

17 K. Bleek and A. Taubert, Acta Biomater., 2013, 9, 6283.

18 S. Eftekharzadeh and S. I. Stupp, Chem. Mater., 1997, 9, 2059.

19 W. X. He, P. Kjellin, F. Currie, P. Handa, C. S. Knee, J. Bielecki, L. R. Wallenberg and M. Andersson, Chem. Mater., 2012, 24, 892.

20 P. Alexandridis, U. Olsson and B. Lindman, Macromolecules, 1995, 28, 7700.

21 P. Holmqvist, P. Alexandridis and B. Lindman, Langmuir, 1997, 13, 2471.

22 F. Abbona, F. Christensson, M. F. Angela and H. E. L. Madsen, J. Cryst. Growth, 1993, 131, 331.

23 J. L. Giocondi, B. S. El-Dasher, G. H. Nancollas and C. A. Orme, Philos. Trans. R. Soc., A, 2010, 368, 1937.

24 D. Volkmer, M. Harms, L. Gower and A. Ziegler, Angew. Chem., Int. Ed., 2005, 44, 639.

25 H. Imai, T. Terada and S. Yamabi, Chem. Commun., 2003, 484.

26 A. Shkilnyy, J. Brandt, A. Mantion, O. Paris, H. Schlaad and A. Taubert, Chem. Mater., 2009, 21, 1572. 